\title{
LEUCEMIA MIELOIDE AGUDA (LMA): AS CONDIÇÕES PSICOLÓGICAS DO PACIENTE ADULTO
}

ACUTE MYELOID LEUKEMIA (AML): THE PSYCHOLOGICAL CONDITIONS OF THE ADULT PATIENT LEUCEMIA MIELOIDE AGUDA (LMA): LAS CONDICIONES PSICOLÓGICAS DEL PACIENTE ADULTO

\author{
Carlos Alberto Domingues Nascimento* \\ Charmênia Maria Braga Cartaxo ${ }^{* *}$ \\ Katiuscia Araújo de Miranda Lopes ${ }^{* *}$ \\ Magaly Bushatsky ${ }^{* * *}$ \\ Alexciana Farias Batista****
}

\begin{abstract}
RESUMO
Este estudo objetivou caracterizar a condição psicológica vivenciada por pacientes adultos em relação à leucemia mieloide aguda (LMA). Para tanto, utilizou-se de uma investigação qualitativa, de natureza descritiva e exploratória, da qual, segundo o critério de saturação do conteúdo, participaram 16 mulheres atendidas num serviço de referência da cidade do Recife-PE, em 2012. Os dados evidenciaram um conhecimento correto e errôneo, baseado, respectivamente, em informações do senso comum e científico. Mostraram, ainda, que os pacientes, ao receberem o diagnóstico, podem apresentar uma condição de desajustamento emocional, por exemplo, recorrendo à negação. Durante o tratamento, todavia, é possível que evoluam para uma condição de ajustamento emocional. Permitiu também observar que o adoecimento induz ao desenvolvimento de atitudes positivas para o estilo e a qualidade de vida. Os dados reforçam a necessidade de que os profissionais de saúde, contrapondo-se a uma perspectiva biomédica, assistam, de forma humanizada, o paciente e seus familiares.
\end{abstract}

Palavras-chave: Neoplasias. Leucemia. Ajustamento emocional. Enfrentamento. Estilo de vida.

\footnotetext{
Texto recebido em 18 de abril de 2013 e aprovado para publicação em 3 de novembro de 2014.

Doutor em Linguística pela Universidade Federal de Pernambuco (UFPE); psicólogo e psicanalista; professor adjunto da Faculdade de Enfermagem Nossa Senhora das Graças (FENSG) da Universidade de Pernambuco (UPE); professor da Residência de Psicologia em Saúde Mental da UPE. Endereço: Rua Marechal Deodoro, 105, ap. 301B - Encruzilhada, Recife-PE, Brasil. CEP: 52030-170.E-mail: minguesnascimento@hotmail.com.

** Doutora em Psicologia da Educação pela Pontifícia Universidade Católica de São Paulo (PUC-SP); psicóloga; professora adjunta do Instituto de Ciências Biológicas (ICB) da Universidade de Pernambuco (UPE); coordenadora da Residência de Psicologia em Saúde Mental da UPE. Endereço: Endereço: Rua Marechal Deodoro, 105, ap. 301B - Encruzilhada, Recife-PE, Brasil. CEP: 52030-170.E-mail: charmenia.cartaxo@bol.com.br.

** Mestra em Ciências da Saúde pela UFPE; enfermeira; professora assistente da FENSG/UPE. Endereço: Rua Leonor Soares Pessoa, 57, ap. 501 - Imbiribeira, Recife-PE, Brasil. CEP: 51170-600.E-mail: walkatylopes@hotmail.com.

**** Doutora em Saúde da Criança e do Adolescente pela UFPE; enfermeira; professora adjunta da FENSG/UPE. Endereço: Avenida Boa Viagem, 296, ap. 1202 - Pina, Recife-PE, Brasil. CEP: 51011-000.E-mail: magab@hotlink.com.br.

${ }^{* * * * *}$ Enfermeira graduada pela FENSG/UPE. Endereço: CNB 11, Lote 14, ap. 512, Taguatinga Norte-DF, Brasil. CEP: $72115-$ 115.E-mail:alexci_2007@hotmail.com.
} 


\section{ABSTRACT}

This study aimed to characterize the psychological condition presented by the adult patients towards the Acute Myeloid Leukemia (AML). For that, a qualitative, descriptive and exploratory investigation was used. According to the saturation of the content, 16 women who assisted at a service of reference by the city of Recife, Pernambuco in 2002, participated in the study. The data detached a conscious knowledge of right and wrong, based, respectively, on information of both common and scientific knowledge. They have also shown that the patients, when became aware of their diagnose, may present a condition of an emotional maladjustment, leaning towards, for instance, denial. Nevertheless, during the treatment it is possible for them to evolve to a condition of an emotional adjustment. The study allowed, also, the observation of the fact that an illness leads to the development of positive attitudes of life. The data reinforced the urgency of a humanized assistance for both the patient and their family to be implemented by the professionals of health, who should be against the biomedical perspective.

Keywords: Neoplasmas. Leukemia. Emotional adjustment. Coping behavior. Lifestyle.

\section{RESUMEN}

Este estudio tuvo por fin caracterizar la condición psicológica vivenciada por pacientes adultos respecto a la leucemia mieloide aguda (LMA). Para esto, se desarrolló una investigación cualitativa, de naturaleza descriptiva y exploratoria, de la cual, según el criterio de saturación del contenido, participaron 16 mujeres atendidas en un servicio de referencia de la ciudad de Recife-PE, en 2012. Los datos evidenciaron un conocimiento correcto y erróneo, basado, respectivamente, en informaciones del sentido común y científico. Mostraron, también, que los pacientes, al recibir el diagnóstico, pueden presentar una condición de desajuste emocional, por ejemplo, recurriendo a la negación. Sin embargo, durante el tratamiento, es posible que evolucionen hacia una condición de ajuste emocional. Permitió, aún, observar que el proceso de enfermarse induce al desarrollo de actitudes positivas para el estilo y la calidad de vida. Los datos refuerzan la necesidad de que los profesionales de salud, contraponiéndose a una perspectiva biomédica, cuiden al paciente y a sus familiares de forma humanizada.

Palabras clave: Neoplasmas. Leucemia. Adaptación emocional. Enfrentamiento. Estilo de vida. 


\section{INTRODUÇÃO}

$\mathrm{O}$ tecido sanguíneo, além de uma parte líquida, o plasma, comporta uma parte sólida, as células ou elementos figurados, que se subdividem em glóbulos brancos (leucócitos), glóbulos vermelhos (hemácias ou eritrócitos) e plaquetas (trombócitos). Essas células são originárias da diferenciação das células-tronco hematopoiéticas, também denominadas de células percussoras, por um processo denominado de hematopoese. A leucemia corresponde ao conjunto de neoplasias malignas resultantes de uma falha na hematopoese, ou seja, quando, ocorrendo uma proliferação e acúmulo excessivo das células percussoras, há um comprometimento no desenvolvimento e no funcionamento das células sanguíneas (Guyton \& Hall, 2006; Junqueira \& Carneiro, 2004). Embora alguns fatores estejam, frequentemente, relacionados à sua ocorrência, tais como genéticos, exposição à radiação/quimioterapia, exposição ao benzeno e síndromes mielodisplásicas, a etiologia ainda é desconhecida (Guyton \& Hall, 2006; Instituto Nacional do Câncer José Alencar Gomes da Silva (INCA, 2014b); Junqueira \& Carneiro, 2004). Em 2014, estima-se a ocorrência de 11.370 casos novos, sendo 5.050 homens e 4.320 mulheres, o que corresponde, respectivamente, a taxas de 5,2/100 mil e 4,24/100 mil novos casos (INCA, 2014a).

A produção das células sanguíneas ocorre na medula óssea ou em órgãos linfoides, como os gânglios linfáticos e o baço. Considerando uma e outra linhagem das células, tem-se, respetivamente, a leucemia mieloide e a leucemia linfoide, podendo a evolução de ambas ser aguda ou crônica, o que perfaz um total de quatro tipos possíveis: leucemia mieloide aguda (LMA) e leucemia mieloide crônica (LMC) e leucemia linfoide aguda (LLA) e Leucemia Linfoide Crônica (LLC) (INCA, 2014b; Lorenzi, D’Amico, Daniel, Silveira \& Buccheri, 2003). Na forma aguda, há uma rápida elevação do número de células sanguíneas imaturas, podendo, caso o tratamento não seja realizado precocemente, ocorrer o óbito em poucos meses. Em relação à forma crônica, observa-se, lentamente, o aumento de células anormais, demorando vários anos para sua manifestação, e, na ausência de tratamento, também ocorre o agravamento e óbito (Guyton \& Hall, 2006; INCA, 2014b; Junqueira \& Carneiro, 2004; Lorenzi et al., 2003).

O tipo mais comum entre adultos é a LMA. Sua manifestação, como a das demais formas de leucemia, é inespecífica, o que faz o seu quadro clínico se confundir com o de outras doenças, podendo, assim, ocasionar a demora do diagnóstico. Os sinais e sintomas mais comuns são, entre outros, anemia, febre, suor noturno, infecções, dores nos ossos e nas articulações, etc. Em alguns tipos, observa-se alterações no volume anatômico dos gânglios (adenomegalias), do 
baço (esplenomegalia) e do fígado (hepatomegalia), além de infiltrações no Sistema Nervoso Central (SNC), nos órgãos e tecidos (Guyton \& Hall, 2006; INCA, 2014b; Junqueira \& Carneiro, 2004; Lorenzi et al., 2003).

Para o tratamento da LMA, que pode durar até um ano, utiliza-se a poliquimioterapia, além do controle das complicações infecciosas e hemorrágicas e a prevenção ou combate da doença no SNC (INCA, 2014b). Em torno de $65 \%$ a $75 \%$ dos pacientes apresentam uma resposta completa após a fase inicial de tratamento, mas apenas $25 \%$ a 30\%, em média, são curados (INCA, 2014a; 2014b). Nessa fase inicial, devido à incapacidade de a medula óssea produzir e maturar as células sanguíneas, realizam-se transfusões de eritrócitos, para corrigir a anemia, e de plaquetas, para prevenir hemorragias. Observe-se, ainda, que a poliquimioterapia, por sua agressividade, favorece a emergência de infecções oportunistas, terminando por ocasionar internações. Outro recurso terapêutico é o transplante da medula óssea, embora se constitua em um procedimento complementar, uma vez que os efeitos colaterais da quimioterapia e, ou, radioterapia podem acarretar o comprometimento múltiplo de órgãos e tecidos e a depressão imunológica (Guyton \& Hall, 2006; Junqueira \& Carneiro, 2004; Lorenzi et al., 2003).

Nos últimos anos, o conhecimento e os avanços tecnológicos sobre o câncer têm favorecido tanto a realização de um diagnóstico rápido e preciso como o surgimento de terapêuticas que propiciam uma maior sobrevida e cura ao paciente, todavia permanece sua associação à morte: "O estigma do câncer imprime sua marca na cultura, e, ainda hoje, a cristalização desse estigma repleto de representações negativas parece não se dissolver" (Barbosa \& Francisco, 2007, p. 15). Para o paciente e seus familiares, o diagnóstico, mesmo que associado a um bom prognóstico, é percebido de forma intensamente negativa, pois coloca as perdas cotidianas e, principalmente, a morte como possibilidades reais (Barbosa \& Francisco, 2007; Campos, 2010).

A comunicação do diagnóstico de câncer, por mais adequada que seja sua realização, termina por configurar uma experiência dramática, permeada de vivências associadas a temores, incertezas e à incredulidade diante da realidade da dor e da morte (Silva \& Zago, 2005). Prevalece para a maioria dos pacientes um estado de desajustamento emocional, o qual pode ser temporário ou se configurar como um transtorno psíquico, por exemplo, a depressão ou a ansiedade (Teng, Humes \& Demetrio, 2005). O câncer, como outras doenças crônicas, é percebido como uma ameaça "à linha de continuidade da vida, das funçôes desempenhadas no dia a dia, de certa previsibilidade que guardamos sobre o dia de amanhã. $\mathrm{O}$ impacto da doença imobiliza e congela a existência e, em consequência, sua relação com o mundo" (Botega, 2006, p. 43-44). Assim, 
desde o diagnóstico e durante o tratamento, o paciente vivencia mudanças comportamentais que interferirão diretamente no seu processo de ajustamento emocional à realidade da doença.

Considerando a necessidade do ajustamento emocional para o enfrentamento do câncer, o estudo objetivou caracterizar a condição psicológica, vivenciada por pacientes adultos em relação à LMA. Priorizou, entre os aspectos possíveis de serem investigados, a abordagem do conhecimento do paciente, a autopercepção do seu estado psicológico no diagnóstico/tratamento e a repercussão do adoecimento no seu estilo e na qualidade de vida.

É importante ressaltar a relevância dos estudos vinculados a essa perspectiva, pois oferecem subsídios para que os profissionais e serviços de saúde efetivem uma assistência humanizada. O conhecimento das condições psicológicas do paciente com leucemia permite subsidiar as ações de um modelo de assistência integral, tal qual preconizado pelo Sistema Único de Saúde (SUS), que reconhece a subjetividade como um campo imprescindível para uma assistência plena ao processo saúde-doença-morte (Ministério da Saúde, 2004; Rios, 2009).

\section{MÉTODO}

O estudo se fundamentou numa abordagem qualitativa de natureza descritiva e exploratória. Essa perspectiva prioriza o levantamento de informações que permitam apreender as significações subjetivas dos sujeitos (percepçôes, motivos, crenças e atitudes) relacionadas ao fenômeno estudado (Minayo, 2004). Assim, levantaram-se as significaçôes dos pacientes adultos sobre a LMA, considerandose, para tanto, o conhecimento sobre a doença, a vivência do diagnóstico/ tratamento e a repercussão no estilo/qualidade de vida.

Para efetivação do estudo, considerou-se uma população/amostra proposital por conveniência de homens e mulheres adultos, todavia, nesse estudo, os dados e as análises foram restritos àqueles relativos às mulheres adultas (Polit, Beck \& Hungler, 2004). Para assegurar a ocorrência, coerência e uniformidade dos dados, as participantes foram selecionadas em função dos seguintes critérios de inclusão:

a) apresentar o diagnóstico de LMA;

b) ser adulta com idade compreendida entre 25 e 50 anos de idade; e

c) estar em tratamento no período de 3 a 6 meses. No que se refere aos critérios de exclusão, considerou-se: 
$\checkmark$ ser portadora de transtorno mental grave e

$\checkmark$ ser gestante. O recrutamento das participantes ocorreu num serviço de referência em hematologia e hemoterapia, localizada na cidade de Recife-PE.

A identificação das participantes se realizou mediante análise dos prontuários, sob a orientação de psicólogos, enfermeiros e médicos do serviço. Ao término da coleta, segundo o critério de saturação do conteúdo, constituiu-se uma amostra de 16 mulheres (Polit, Beck \& Hungler, 2004). Uma vez selecionadas, todas as participantes foram submetidas a uma entrevista semiestruturada, previamente testada, com as seguintes temáticas:
a) conhecimento sobre a leucemia;
b) enfrentamento do diagnóstico e do tratamento; e
c) repercussões no estilo e na qualidade de vida. As entrevistas foram reali- zadas individualmente e em lugares diversos, mas sempre em condiçôes ambientais adequadas de iluminação, temperatura, sonoridade, sigilo, etc.

Os dados, após a transcrição das entrevistas, foram analisados e categorizados por três pesquisadores, recorrendo-se, para tanto, ao método do Discurso do Sujeito Coletivo (DSC), cujas figuras metodológicas resgatam e organizam a significação coletiva com base na articulação e relação daquelas individuais (Lefévre \& Lefévre, 2005). Para tanto, têm-se as seguintes etapas:

a) identificação de expressões-chave (E-Ch): trechos que melhor identificam e descrevem o conteúdo significativo e comum para os diversos indivíduos;

b) síntese das ideias centrais (ICs): fórmulas sintéticas que descrevem o significado (comum, complementar ou oposto) presente nos discursos;

c) estabelecimento das ancoragens (ACs): formulações sintéticas, decorrentes das marcas discursivas que permitem identificar e articular o contexto ideológico, subjacente ao discurso formulado; e

d) edição dos DSC: articulação das E-Ch e suas respectivas ICs e, ou, ACs, mediante a edição de textos na primeira pessoa do singular, os quais são representativos dos indivíduos e do grupo. 
Durante a análise, cada pesquisador realizou, individualmente, a identificação preliminar das E-Ch e das ICs, as quais, uma vez comparadas, acarretaram o estabelecimento daquelas definitivas. Em razão destas, cada pesquisador procedeu, inicialmente, à edição prévia dos DSCs, para, em seguida, comparando-as, operar a edição final. Nesse contexto, tem-se que as ICs/DSCs são formulações sintéticas, que expressam, em relação aos pacientes com leucemia, suas significações sobre o processo de adoecimento. A focalização do conteúdo, cujo alvo é a dimensão subjetiva, permitiu desconsiderar a análise das marcas de ancoragem. Constituído o conjunto dos DSCs, todos os pesquisadores, considerando a pesquisa bibliográfica realizada e as inferências suscitadas, contribuíram para a discussão dos resultados.

A pesquisa, desenvolvida em 2012, foi previamente avaliada e aprovada pelo Comitê deÉtica em Pesquisa (CEP) da Fundação Hemope (Parecer no . 035/2009). Cada participante, antes de formalizar sua colaboração, mediante assinatura do Termo de Consentimento Livre e Esclarecido (TCLE), foi informado sobre o objetivo do estudo, o sigilo de seus dados pessoais, a necessidade da gravação das entrevistas e a posterior divulgação científica dos resultados.

\section{RESULTADOS E DISCUSSÃO}

As 16 participantes, entre outras características, apresentaram as seguintes:

a) faixa etária entre 27 e 48 anos;

b) donas de casa e comércio; e

c) o período de diagnóstico/tratamento de 3 a 4 meses. A discussão dos resultados não considerou a estratificação da amostra com base em tais características, pois, como proposto no objetivo do estudo, o foco, por se tratar de um estudo qualitativo, foi o conjunto das significações subjetivas dos pacientes sobre a LMA. As entrevistas permitiram a edição de 15 ICs com seus respectivos DSCs.

\section{CONHECIMENTO SOBRE LEUCEMIA}

No âmbito social, a representação sobre o adoecimento encontra-se repleta de informações oriundas tanto do meio erudito (religioso, científico, filosófico, etc.) como do senso comum (tradições, costumes, hábitos, etc.) (Reis \& Fradique, 2004). Uma e outra informação coexistem, mantendo uma relação de concordância, complementaridade e oposição. A representação sobre a doença, 
como a da saúde e da morte, resulta do intercâmbio das inúmeras práticas, crenças e valores historicamente construídos com base nessas duas formas de conhecimento (Gomes, Mendonça \& Pontes, 2002; Reis \& Fradique, 2004). No caso da representação pessoal, aquela de cada um sobre o seu processo de saúde, adoecimento e morte, tem-se a articulação das representações sociais com as impressões vividas e experienciadas individualmente, ou seja, evidenciam a junção do subjetivo com o coletivo.

Contudo, em certas situações, as crenças populares podem repercutir, de maneira mais enfática, na construção da representação do adoecimento, o que geralmente ocorre quando se trata de uma patologia de grande propagação como hanseníase, síndrome da imunodeficiência adquirida (AIDS), sarampo, câncer, etc. Na leucemia, em particular, também se observa a divulgação de informações oriundas do senso comum e da ciência (Coutinho \& Trindade, 2006). Constroem-se, assim, representações que, conjugando-se ambas, articulam crenças corretas e errôneas. Como consequência, tem-se, por exemplo, não somente a representação que, corretamente, classifica a leucemia como um tipo de câncer, mas também aquela que, erroneamente, pelo estigma associado ao câncer, termina por concebê-la como incurável, sendo a morte inevitável. Um equívoco que se estende a sua etiologia, pois sua origem é atribuída a uma anemia: "DSC I - Informaçóes distorcidas: Sabia que era câncer no sangue. Era sangue fraco, que a pessoa não se alimenta bem, direito, e que da anemia virava leucemia. O sangue vira água. E escutei dizer que ainda não, por enquanto, num tem cura."

Por outro lado, observa-se um conhecimento coerente com o prognóstico do tratamento da leucemia, especialmente no que se refere à expectativa de remissão e cura. Dessa forma, a associação leucemia-câncer-morte é apreendida como uma possibilidade real, embora não seja tida como necessária e única, dando-se também a percepção da possibilidade de sua cura ou da sobrevida. É uma percepção que condiz com os dados clínicos da leucemia, pois, no caso do paciente com LLA, cuja ocorrência é mais comum na infância, o percentual de remissão e cura é, para a faixa etária de 2 a 10 anos, maior que $85 \%$, e para aqueles com LMA, embora a taxa seja menor, entre $25 \%$ e $30 \%$, também se evidencia uma real possibilidade da cura (INCA, 2014a). Os participantes mostram, assim, um conhecimento realista do prognóstico:

DSC II - Informaçóes fidedignas: Em alguns casos, têm cura e outros não. Sabia que tinha que fazer quimioterapia, mas não sabia que existiam outros tipos nem como seria [todo] o tratamento. Soube de alguém que teve, fez o tratamento e morreu. Ouvi falar através da novela. 
$\mathrm{Na}$ saúde, a prática educativa e preventiva pressupõe a divulgação de informaçôes que agreguem tanto o saber do senso comum como o científico. No caso da leucemia, essa divulgação é de suma importância, pois o diagnóstico precoce e diferencial é um dos fatores mais significativos para a definição do tratamento e, portanto, a efetivação de um prognóstico mais favorável. A propagação de informações cientificamente pertinentes é um fator relevante, para que se tenha acesso imediato e eficaz ao conjunto de tratamentos da leucemia.

\section{ENFRENTAMENTO DO DIAGNÓSTICO E DO TRATAMENTO}

O desajustamento emocional diante do diagnóstico de uma doença, crônica ou aguda, relaciona-se às privações oriundas das limitações físicas e psíquicas impostas pelo adoecer, além daquelas associadas ao temor diante da possibilidade de dor e morte. O adoecer define um estado real ou imaginário de privação, de perda subjetiva e objetiva de si e dos demais objetos como gratificantes. Em oposição à saúde, constitui-se em uma condição de frustração e de sofrimento.

Considerando-se a expectativa de perda que o câncer gera, é por ele estabelecida uma condição de desajustamento e sofrimento veiculado a reaçôes emocionais negativas, como ansiedade, agressividade, depressão, tristeza, etc. (Vasconcelos, Costa \& Barbosa, 2008). As participantes demonstram que, desde a comunicação do diagnóstico, já se observa essa condição, pois era desencadeado um intenso estado de angústia, também caracterizado por um sentimento de desesperança, um sentimento de culpa com ideias autorrecriminadoras e reaçōes somáticas, tais como fadiga, tremor e perda de sono:

DSC III - Conturbação emocional diante da doença: Levei um susto, foi terrível, fiquei desesperada, como se tivesse levado uma pisa. Fui para fora do consultório e chorei. Achei que tinha pouco tempo de vida, minha cabeça ficou perturbada, fiquei trêmula. Não dormi à noite. Pensei onde foi que errei, onde foi que deixei de ter atenção comigo. O pior momento da minha vida; até parecia que o mundo estava acabando. Fiquei sem chão. A gente nunca pensa que isso pode acontecer com a gente.

Para os participantes do estudo, dentre as reações emocionais de desajustamento, destaca-se o sentimento de raiva como protesto devido à necessidade de internamento, para a realização das sessões de poliquimioterapia. Na realidade, a expectativa era de que ela não ocorresse. Mostra-se, assim, uma grande frustração pelo distanciamento ou pela privação da realização dos interesses cotidianos: 
DSC IV - Reaçôes de raiva diante do tratamento: Fiquei com raiva ao saber que ia ficar internada e que o tratamento era prolongado. Pensei que faria a quimioterapia e iria embora para casa. Vinha fazer medicação e voltava. Pensei que era pouco tempo de tratamento.

Diante das situações de adoecimento grave, podem emergir pensamentos disfuncionais catastróficos (estimam a ocorrência do pior) e divinatórios (veiculam expectativas prioritariamente negativas) (Costa \& Leite, 2009; Silva, Aquino \& Santos, 2008). Esse tipo de pensamento, que compromete a avaliação precisa da doença e suas reais condições de cura (ou sobrevida), coloca a morte como inexorável. Concomitantemente, contribui para intensificar o medo diante da restrição ou rejeição do convívio sociofamiliar e da limitação da realização dos afazeres cotidianos: "DSC V - Expectativas negativas diante do adoecimento: Pensei que, de uma hora para outra, iria morrer. Que ia morrer e não iria conseguir vencer [a doença]. Não seria aceita pelas pessoas. Iria ficar sem fazer as coisas, sem ver os filhos."

O ser humano, quando vitimado por uma doença grave, é acometido por questionamentos existenciais que buscam dar significação ao sentimento de finitude com o qual é confrontado (Botega, 2006). Desprovidos de respostas imediatas e objetivas, esses questionamentos parecem expressar a angústia diante das ameaças de perdas impostas pela doença: a perda de si e dos outros. $\mathrm{O}$ paciente, como demonstra os participantes, vivencia essa angústia com base em ideias autorrecriminatórias e autopunitivas, sendo o adoecimento o "castigo" que se recebe pelo descuido de si. Também, num apelo velado ao religioso, veem-no como uma "injustiça" da qual são as vítimas. Há, inclusive, a supervalorização do autoconceito e, ao mesmo tempo, a diminuição do altruísmo, em que a justeza do adoecimento é posta em questão, e, sem culpabilidade, desejada a outro, como se perguntassem: Por que comigo, que não mereço, e não com aquele realmente merecedor? A vivência do adoecimento é apreendida com culpa e como retaliação:

DSC VI - O adoecimento como uma ocorrência punitiva: Pensei: aonde foi que errei, onde foi que parei, deixei de ter atenção comigo? Porque tem tanta gente ruim e estão bem, vendendo saúde, enquanto vivo para família e, de repente, me vejo num lugar deste. Quando soube que tinha que ficar internada disse: não sou má filha, não sou má vizinha.

Essa condição de desajustamento emocional, pautada em estados emocionais negativos, pensamentos disfuncionais e sentimento de retaliação, pode não ser imediatamente manifesta, substituindo-a por uma ação defensiva inadequada, ou seja, a utilização do mecanismo da negação mediante o qual se opera a subtração 
da ameaça real e evidente, evitando-se o sofrimento. Ao mesmo tempo, pode-se postular que não se trata de negação, mas de desinformação sobre a gravidade da doença e sua possibilidade de acarretar a morte ou impor, pelo caráter invasivo do tratamento, no caso da poliquimioterapia, experiências dolorosas e mudanças na condição física, particularmente na imagem corporal, e nos afazeres diários:

DSC VII - Descaracterização da gravidade da doença: Fiquei tranquila por não ter conhecimento. Cantei. Não fiquei triste. Não tinha muita informação sobre a doença. Mesmo depois que estava na enfermaria, que a médica disse o diagnóstico, não fiquei impressionada. Demorou a cair a ficha.

Mas nem sempre as reações emocionais são desajustadas, sendo possível constatar, também, expectativas e atitudes otimistas quanto à manutenção das atividades da vida cotidiana e da cura (Botega, 2006; Gambatto, Carli, Guarienti, Silva \& Prado, 2006; Silva, S. S., 2008). É possível, nessas situações, postular uma ação defensiva positiva adequada; por exemplo, a racionalização que, recorrendo às crenças religiosas, fundamenta uma explicação coerente para o adoecimento, e, ao mesmo tempo, a possibilidade de sua cura. Introduz-se, assim, um ajustamento emocional, pois o diagnóstico é percebido positivamente, como um "achado clínico" benéfico, que favorece a restauração da saúde. Criase uma condição psíquica que ameniza o sofrimento, tornando suportável tanto o diagnóstico como o tratamento: "DSC VIII - Atitude otimista diante do adoecimento: Agradeci a Deus: obrigada, Jesus, por eu ter descoberto o que tinha. A única coisa que pensei é que eu ia ficar boa, que eu ficaria curada, e eu não poderia pensar em outra coisa, de outra forma."

Outro aspecto que se observa, algumas vezes, já a partir do diagnóstico, e não mais como racionalização, é o fortalecimento do vínculo religioso propriamente dito e, com este, uma maior confiança na eficácia do tratamento (Costa \& Leite, 2009; Fornazari \& Ferreira, 2010). Nas situações de adoecimento, a partir da gravidade do quadro clínico ou da possibilidade de morte, o que é o caso da leucemia, pode haver a intensificação do sentimento de impotência ou incapacidade, sendo a religiosidade, qualquer que seja sua forma de ocorrência, um fator que efetivamente favorece a restituição da autoconfiança, possibilitando, assim, condição adequada para o alívio do sofrimento vivenciado. É como se o ato de fé em Deus e, mais especificamente, em sua onipotência, ou seja, na incomensurabilidade de seu poder, apaziguasse a fragilidade pessoal diante da doença e da morte. Os participantes sublinham essa relevância da religiosidade como suporte emocional, deixando transparecer sua função protetora e de ajustamento psíquico: 
DSC IX - Intensificação do sentimento de religiosidade: Depois do diagnóstico, enxerguei mais a Deus, a fé aumentou. Se a pessoa não tiver fé em Deus, quem vai nos levantar? Busquei mais esclarecimento com relação à fé. Estou mais próximo de Deus. Tinha muita fé em Deus e agora tenho mais ainda.

O diagnóstico e o tratamento, como observado, acarretam uma vivência angustiante, todavia não se trata de uma condição psíquica de todos os pacientes, havendo, como demonstram alguns participantes, aqueles que conseguem, de imediato, reagir de forma emocionalmente ajustada à doença, apesar de seu caráter ameaçador. Operam a inversão afetiva do estado negativo: medo/ ansiedade - para um positivo, ou seja, normalidade/tranquilidade:

DSC X - Aceitação do processo de adoecimento: Fiquei normal. Tem gente que depende de mim, não posso me entregar à doença, não posso ceder. Não fiquei impressionada, fiquei tranquila, fiquei calma. Fiz uma promessa, disse que não poderia me entregar por nada.

O adoecimento desencadeia, inicialmente, uma condição de desajustamento emocional que, muitas vezes, se não for precocemente identificada e cuidada, pode se acentuar. Mas, no transcorrer do tratamento, o próprio paciente pode empreender uma ação de ajustamento, ou, havendo o apoio emocional por parte dos amigos, familiares e profissionais de saúde, desenvolver uma prática preventiva que evite ou amenize o desenvolvimento de transtornos psíquicos ou da intensificação do sofrimento. $\mathrm{O}$ foco no ajustamento emocional deve ser um dos parâmetros orientadores do apoio psicológico ao paciente.

\section{REPERCUSSÕES NO ESTILO DE VIDA}

Familiares e amigos também vivenciam uma condição de desajustamento emocional análoga à do paciente, posto que a ameaça de perdê-lo, pelo vínculo afetivo que mantém com ele, é uma ameaça real (Ferreira, Dupas, Costa \& Sanchez, 2010; Franco, 2008; Lucchese, 2003; Melo et al., 2012). Os participantes enfatizam a relevância da manutenção e do reforço do vínculo sociofamiliar como apoio emocional. Atento ao sofrimento, o meio sociofamiliar, na maioria das vezes, propicia o apoio emocional necessário ao paciente com leucemia ou outras formas de neoplasia. 
DSC XI - Apoio de familiares e amigos: O relacionamento com a família está igual ou até melhorou, pois eles dão muita força. Estamos até mais unidos. Já éramos muito unidos. Com os amigos e os vizinhos permanece o mesmo. Os vizinhos são bons. Recebo apoio de todos.

Embora ocorra o apoio emocional da família, é importante enfatizar que as demandas impostas pela doença, especialmente no que se refere às situações de privação, por exemplo, financeira e de lazer, podem influenciar negativamente os membros da família, dificultando o apoio emocional que prestam ao paciente, o que mostra a necessidade de também serem apoiados (Sanchez, Ferreira, Dupas \& Costa, 2010). Doenças crônicas, como a leucemia, de tratamento prolongado, modificam o cotidiano de todos, inclusive o dos familiares, comprometendo-lhes o bem-estar.

A poliquimioterapia é um dos motivos que levam ao internamento do paciente, pois, após sua realização, torna-se necessário isolá-lo fisicamente, já que a redução do número de leucócitos e, consequentemente, a baixa da imunidade, favorecem o surgimento de infecções (Otto, 2002; Smeltzer \& Bare, 2005). Complicações decorrentes do tratamento e da doença também podem ocasionar sucessivos internamentos ou a extensão de sua duração. Nessas circunstâncias, o paciente, como se observa com crianças e adolescentes, afasta-se do ambiente familiar, acentuando-se seu sofrimento (Cicogna, Nascimento \& Lima, 2010). Dependendo da distância entre a região onde resida e aquela na qual realize o tratamento, pode ocorrer um maior distanciamento dos amigos e familiares, especialmente os filhos. $\mathrm{O}$ isolamento físico, que é uma medida preventiva do tratamento, pode ocasionar um isolamento familiar, além de social, já que restringe o convívio com familiares e amigos:

DSC XII - O internamento e o distanciamento sociofamiliar: Tive de me afastar das pessoas por causa dos internamentos. É ruim a distância dos filhos. O maior impacto é a distância dos filhos. Não é que o tratamento seja ruim, o pessoal é atencioso, mas é difícil ficar internado.

Como o tratamento quimioterápico interfere na capacidade funcional do paciente, observa-se uma perda de sua autonomia e o aumento da dependência dos familiares para a realização das atividades de autocuidado, como higiene e alimentação. Dessa forma, ocorre uma limitação da atividade física, a qual é permeada por sentimentos de impotência e inutilidade: 
DSC XIII - Comprometimento da realização das atividades cotidianas: Minha rotina mudou, a vida ficou limitada, achei que não ia fazer mais nada em minha vida. Antes quem resolvia as coisas era eu, hoje, dependo dos outros, não posso fazer mais certas coisas que fazia antes, me sinto uma inútil. Meus filhos preparam a comida. Não arrumo mais a casa. Não faço caminhada.

Por outro lado, a doença e o tratamento podem desempenhar uma função motivadora para o cuidado com a saúde, levando ao desenvolvimento de atitudes saudáveis no âmbito da alimentação, lazer, período de trabalho, exercício físico etc. Surge uma demanda pelo autocuidado e, assim, sem desmerecer uma perspectiva altruísta, os pacientes passam a enfatizar a valoração da atenção das suas necessidades pessoais, particularmente do seu bem-estar físico:

DSC XIV - Preocupação e valorização da própria saúde: Passei a olhar para mim, o que antes não fazia, cuidava dos outros e esquecia de mim. Hoje, tenho consciência que tenho que cuidar de mim, para depois cuidar dos outros. Passei a ter mais preocupação com minha saúde; antes não gostava de ir ao médico. Agora o dinheiro que tenho não vou mais usar para comprar mais nada, usarei para comida, para remédio.

No que pese, inicialmente, a perspectiva da morte, com o transcorrer do tratamento, essa ideação pode ser suplantada, ocorrendo uma gradativa restituição dos projetos e planos futuros, o que torna a cura, mais do que a morte, uma expectativa possível de concretização:

DSC XV - Reorganização dos interesses pessoais: Quando descobri a doença, achei que não ia fazer mais nada em minha vida, porque ia morrer, então para que fazer? Mas, agora, continuo pensando em fazer tudo o que planejei. Não desisti de meus planos futuros. Penso em trabalhar menos e me dedicar mais à família.

Cada vez mais se torna consensual a importância do desenvolvimento de ações educativas em saúde não somente na perspectiva preventiva e curativa das doenças como também de sua promoção, favorecendo-se a conscientização da população sobre a importância da aquisição de atitudes saudáveis para a melhoria da qualidade de vida. $\mathrm{O}$ estímulo a tais atitudes, mesmo quando o adoecimento, grave ou crônico, já esteja diagnosticado, contribui para o seu enfrentamento, principalmente das consequências advindas do tratamento, por exemplo, o surgimento de infecçôes, tal qual se observa na AIDS ou nas hepatites, e, evidentemente, na leucemia (Otto, 2002; Smeltzer \& Bare, 2005). 


\section{CONSIDERAÇŌES FINAIS}

A leucemia, como todos os tipos de câncer, comporta uma representação social e pessoal, na qual o adoecimento e a morte prevalecem como uma vivência imediata de perdas e privações, que, deslocando-se do plano imaginário, materializa-se no concreto da vida cotidiana. Nesse contexto, é provável, ainda que não seja necessário, um estado inicial de desajustamento emocional no paciente e nos seus familiares. A doença, ao redimensionar a linha existencial, esgotando o presente e abreviando o futuro, exige um período de adaptação.

Um dos fatores que contribuem para a efetivação dessa adaptação é o conhecimento sobre a leucemia. Constatou-se, então, que as informações oriundas do senso comum e do meio científico comportam conteúdos corretos e errôneos sobre o diagnóstico e o tratamento bem como das características clínicas da leucemia. No geral, prevalece certo desconhecimento sobre a doença, o que mostra a necessidade da propagação midiática de novas informações que contribuam para a prevenção, formulação do diagnóstico e eficácia do tratamento. Sobre o tratamento, em particular, ainda prevalece uma estreita vinculação da leucemia à morte, desconhecendo-se os inúmeros avanços que têm permitido sua cura e uma maior sobrevida.

Com o diagnóstico e o tratamento da leucemia, é possível observar reações emocionais de desajustamento e ajustamento. Para o desajustamento, temos aquelas vivências associadas a sentimentos negativos, como tristeza, raiva, impotência e desesperança, as quais, inicialmente, configuram uma baixa expectativa sobre a eficácia do tratamento e, portanto, da cura, levando-se à percepção da morte como inevitável. São sentimentos que se fazem acompanhar de pensamentos disfuncionais (catastróficos e divinatórios), da percepção do adoecimento como uma retaliação ou punição e da recorrência à negação como estratégia defensiva.

Essa condição de desajustamento pode ser transitória, ocasionando, então, um processo de ajustamento no qual, sem se desconsiderar a ameaça real de morte representada pela leucemia, opera-se a elaboração de uma atitude positiva diante do tratamento, e, portanto, a possibilidade de cura. Para tanto contribuem a racionalização do processo de adoecimento e a supervalorização da religiosidade, independentemente do credo religioso. Ao mesmo tempo, pode ocorrer uma inversão afetiva, segundo a qual os sentimentos inicialmente negativos são positivados, enfatizando-se, então, a esperança na superação da doença e na efetivação da cura. 
Em relação às repercussões da leucemia na condição de vida do paciente, sobressai a importância do acolhimento familiar e do apoio social dado por amigos e vizinhos. Talvez, pelo conhecimento da gravidade do câncer, observamse, em princípio, atitudes solidárias espontâneas que propiciam um bom suporte emocional, comportamental e material ao paciente. A manutenção e a estimulação desse suporte são extremamente relevantes, pois a debilidade ocasionada pela doença e pelo tratamento impõe limitações físicas e psíquicas, que, se não forem assistidas, contribuem para manter ou intensificar o desajustamento emocional. Tanto é assim que uma das queixas prevalentes é que, em razão do tratamento, com a internação para a quimioterapia, ocorre o afastamento do convívio sociofamiliar. Por outro lado, observa-se que a doença acarreta questionamentos e atitudes direcionadas a reformulações no estilo de vida e, consequentemente, de sua qualidade. Evidencia-se um maior interesse e uma maior preocupação com a valorização da saúde bem como a reorganização de atitudes pessoais, favorecendo, assim, a uma melhoria no autoconceito, uma valorização narcísica.

Os profissionais de saúde (médicos, enfermeiros, assistentes sociais, psicólogos, etc.) devem estar devidamente capacitados para diagnosticar a leucemia, pois se trata de uma doença que não apresenta um sinal ou sintoma patognomônico. Também é preciso que estejam atualizados e aptos à aplicação do protocolo de tratamento, já que nele reside a possibilidade concreta da cura. Tais necessidades, que são imprescindíveis, atendem ao pressuposto de uma assistência biomédica. Todavia o que se constatou é que, além da abordagem técnica e organicista, também é imprescindível enfatizar a condição psicológica, para, assim, propiciar uma assistência humanizada, a qual permita ao paciente, desde o diagnóstico, transitar de uma condição de desajustamento emocional para uma de ajustamento. Dessa forma, é importante que a assistência seja estruturada com profissionais sensíveis e preparados para identificar e intervir sobre o estado emocional do paciente e seus familiares, minimizando-lhes o sofrimento e criando condições psicológicas para o enfrentamento da doença ou, sendo o caso, da morte.

Este estudo pressupõe a consideração de algumas limitações. Observe-se, assim, que as vivências identificadas, bem como as análises realizadas, focalizaram mulheres adultas. Dessa forma, outras condições de gênero e do ciclo de vida, por exemplo, homens e crianças, poderão contribuir com dados e interpretações distintas e complementares. Por outro lado, a observância da estratificação dos sujeitos, com base em variáveis como escolaridade, religião, duração do tratamento, tipo de leucemia, etc., também sugere outras perspectivas de análise. Tais limitações são, por si mesmas, sugestôes para estudos que ampliem a compreensão da temática. Todavia, apesar de tais limitações, é importante frisar a relevância do estudo, pois contribui para a melhoria da assistência ao 
paciente com leucemia e, também, daqueles que vivenciam outros processos de adoecimento, especialmente no âmbito das neoplasias malignas. 


\section{REFERÊNCIAS}

Barbosa, L. N. F. \& Francisco, A. L. (2007). A subjetividade do câncer na cultura: implicações na clínica contemporânea. Revista SBPH, 10(1), 9-24.

Botega, N. J. (2006). Reação à doença e à hospitalização. In N. J. Botega (Org.), Prática psiquiátrica no hospital geral: interconsulta e emergência. (pp. 49-66). Porto Alegre: Artmed.

Campos, E. M. P. (2010). A psico-oncologia. Boletim da Academia Paulista de Psicologia, 30(79), 440-449.

Cicogna, E. C., Nascimento, L. C. \& Lima, R. A. G. (2010). Crianças e adolescentes com câncer: experiências com a quimioterapia. Revista LatinoAmericana de Enfermagem, 18(5), 864-872.

Costa, P. \& Leite, R. C. B. O. (2009). Estratégias de enfrentamento utilizadas pelos pacientes oncológicos submetidos à cirurgia mutiladora. Revista Brasileira de Cancerologia, 55(4),355-364.

Coutinho, B. B. \& Trindade, Z. A. (2006). As representações sociais de saúde no tratamento da leucemia e linfoma. Psic: Revista da Vetor Editora, 7(1), 9-18.

Ferreira, N. M. L., Dupas, G., Costa, D. B. \& Sanchez, K. O. L. (2010). Câncer e família: compreendendo os significados simbólicos. Ciência, Cuidado e Saúde, 9(2), 269-277.

Fornazari, S. A. \& Ferreira, R. R. (2010). Religiosidade/espiritualidade em pacientes oncológicos: qualidade de vida e saúde. Psicologia: Teoria e Pesquisa, 26(2), 265-272.

Franco, M. H. P.(2008). A família em psico-oncologia. In V. A. Carvalho, M. J. Kovacs \& M. H. P. Franco (Orgs.), Temas em psico-oncologia. (pp. 358-362). São Paulo: Summus.

Gambatto, R., Carli, F. C., Guarienti, R. F., Silva, A. L. P. \& Prado, A. B. (2006). Mecanismos de defesa utilizados por profissionais de saúde no tratamento de câncer de mama. Psicologia para a América Latina, 6, 23-31. Recuperado a partir de http://pepsic.bvsalud.org/scielo.php?script=sci_arttext\&pid=S1870350X2006000200005

Gomes, R., Mendonça, E. A. \& Pontes, M. L. (2002). As representações sociais e a experiência da doença. Cadernos de Saúde Pública, 18(5), 1207-1214. 
Guyton, A. C. \& Hall, J. E. (2006). Resistência do organismo à infecção: leucócitos, granulócitos, sistema dos monócitos-macrófagos e inflamação. In A. C. Guyton \& J. E. Hall (Eds.), Tratado de fisiologia médica. (pp. 429-437). Rio de Janeiro: Elsevier.

Instituto Nacional do Câncer José Alencar Gomes da Silva. (2014a). Estimativa 2014: incidência de câncer no Brasil. Rio de Janeiro: INCA. Recuperado a partir de http://www.inca.gov.br/rbc/n_60/v01/pdf/11-resenha-estimativa2014-incidencia-de-cancer-no-brasil.pdf

Instituto Nacional do Câncer José Alencar Gomes da Silva. (2014b). Leucemia. Rio de Janeiro: INCA. Recuperado a partir de http://www2.inca.gov.br/wps/ $\mathrm{wcm} /$ connect/tiposdecancer/site/home/leucemia.

Junqueira, L. C. U. \& Carneiro, J. (2004). Hemocitopoese. In L. C. U Junqueira \& J. Carneiro (Eds.), Histologia básica. (pp. 238-253). Rio de Janeiro: Guanabara-Koogan.

Lefévre, F. \& Lefévre, M. A. (2005). Depoimentos e discursos: uma proposta de análise e pesquisa social. Brasília: Líber Livro.

Lorenzi, T. F., D’Amico, E. D., Daniel M. M., Silveira P. A. A. \& Buccheri, V. (2003). Patologia dos Leucócitos. In T. F. Lorenzi, E. D. D’Amico, M. M. Daniel, P. A. A. Silveira \& V. Buccheri (Eds.), Manual de hematologia: propedêutica e clínica. (pp. 295-498). Rio de Janeiro: Medsi.

Lucchese, A. C. (2003). Famílias: clientes do hospital? - o adoecer e a crise familiar. In M. A. de Marcos (Org.), A face humana da medicina: do modelo biomédico ao modelo biopsicossocial. (pp. 172-173). São Paulo: Casa do Psicólogo.

Melo, M. C. B., Barros, E. N., Campello, M. C. V. A., Ferreira, L. Q. L., Rocha, L. L. C. Silva, C. I. M. G. \& Santos, N. T. F. (2012). O funcionamento familiar do paciente com câncer. Psicologia em Revista, 18(1), 73-89.

Minayo, M. C. S. (2004). Pesquisa social: teoria, método e criatividade. Petrópolis: Vozes.

Ministério da Saúde. (2004). Política Nacional de Humanização do Ministério da Saúde: a humanização como eixo norteador das práticas e gestão em todas as instâncias do SUS. Brasília: Ministério da Saúde [Série B. Textos Básicos de Saúde].

Otto, S. E. (2002). Oncologia. Rio de Janeiro: Reichmann e Affonso. 
Polit, D. F., Beck, C. T. \& Hungler, B. P. (2004). Fundamentos de pesquisa em enfermagem: métodos, avaliação e utilização. Porto Alegre: Artmed.

Reis, J. \& Fradique, F. (2004). Significações leigas de saúde e de doença em adultos. Análise Psicológica, 22(3), 475-485.

Rios, I. C. (2009). Humanização: a essência da ação técnica e ética nas práticas de saúde. Revista Brasileira de Educação Médica, 10(2), 253-261.

Sanchez, K. O. L., Ferreira, N. M. L. A., Dupas, G. \& Costa, D. B. (2010). Apoio social à família do paciente com câncer: identificando caminhos e direções. Revista Brasileira de Enfermagem, 63(2), 290-299.

Silva, L. C. (2008). Câncer de mama e sofrimento psicológico: aspectos relacionados ao feminino. Psicologia em Estudo, 13(2), 231-237.

Silva, S. S. (2008). O paciente com câncer: cognições e emoções a partir do diagnóstico. Revista Brasileira de Terapias Cognitivas, 4(2), 73-88.

Silva, S. S., Aquino T. A. A. \& Santos, R. M. (2008). O paciente com câncer: cognições e emoções a partir do diagnóstico. Revista Brasileira de Terapias Cognitivas, 4(2), 73-88.

Silva, V. C. E. \& Zago, M. M. F. (2005). A revelação do diagnóstico de câncer para profissionais e pacientes. Revista Brasileira de Enfermagem, 58(4), 476480 .

Smeltzer, S. C. \& Bare, B. G. (2005). Histórico e tratamento de pacientes com distúrbios hematológicos. In S. C. Smeltzer \& B. G. Bare, Tratado de enfermagem médico-cirurgica. (pp. 918-991). Rio de Janeiro: Guanabara Koogan.

Teng, C. T., Humes, E. C. \& Demetrio, F. N. (2005). Depressão e comorbidades clínicas. Revista de Psiquiatria Clínica, 32(3), 149-159.

Vasconcelos, A. S., Costa, C. \& Barbosa, L. N. F. (2008). Do transtorno de ansiedade ao câncer. Revista SBPH, 11(2), 51-71. 